\title{
Transanal endoluminal repair for anastomotic leakage after low anterior resection
}

\author{
Yi-Chang Chen' ${ }^{1}$, Yuan-Yao Tsai ${ }^{1}$, Tao-Wei Ke ${ }^{1}$, Abe Fingerhut ${ }^{2,3}$ and William Tzu-Liang Chen ${ }^{4 *}$
}

\begin{abstract}
Background: There is still no consensus on the management of colorectal anastomotic leakage after low anterior resection. The goal was to evaluate the outcomes of patients who underwent transanal endoluminal repair + laparoscopic drainage \pm stoma vs. drainage only \pm stoma.

Methods: Retrospective chart review of patients sustaining anastomotic leakage after laparoscopic low anterior resection between January 2013 and September 2020 who required laparoscopic reoperation.

Results: Forty-nine patients were included, 22 patients underwent combined laparoscopy and transanal endoluminal repair and 27 patients had drainage with a stoma $(n=16)$ or drainage alone $(n=11)$, without direct anastomotic repair. The overall morbidity rate was $30.6 \%$ and the mortality rate was $2 \%$. Combined laparoscopic lavage/drainage and transanal endoluminal repair of anastomotic leakage was associated with a lower complication rate (13.6\% vs. $44.4 \%, p=0.03)$ and fewer intraabdominal infections ( $4.5 \%$ vs. $29.6 \%, p=0.03)$ compared with no repair.

Conclusions: Combined laparoscopic lavage/drainage and transanal endoluminal repair is effective in the management of colorectal anastomosis leakage and was associated with lower morbidity —in particular intraabdominal infection-compared with no repair. However, our results need to be confirmed in larger, and ideally randomized, studies.
\end{abstract}

Keywords: Transanal endoluminal repair, Colorectal anastomosis, Anastomosis leakage, Low anterior resection

\section{Introduction}

Anastomotic leakage is one of the most dreaded complications after elective colorectal surgery and is associated with high morbidity, mortality and poor oncological outcome [1-4]. Despite well-recognized preventive measures, the overall leakage rate ranges from 1 to $22 \%$, while extra-peritoneal anastomosis leakage rates range from 3 to 19\% [5-7]. Treatment strategies differ according to whether the leak is extra-peritoneal or intra-peritoneal [8]. Traditionally, extra-peritoneum anastomosis failure calls for resection with end stoma creation, but which is

*Correspondence: t44112@hotmail.com

${ }^{4}$ China Medical University Hsinchu Hospital, Zhubei, Taiwan

Full list of author information is available at the end of the article never reversed in $12-56 \%$ of patients [8]. Recently there has been a paradigm shift from resection to preservation of the anastomosis [8-10]. The advantage of anastomotic preservation is to avoid an additional resection, the risk of anastomotic leakage when intestinal continuity is finally re-established, and the fact that many patients with the Hartmann procedure do not have stoma reversal [11].

We have previously reported that combined repeat laparoscopy and transanal endoluminal anastomosis repair after colorectal anastomosis leakage was safe and feasible [12, 13]. However, to the best of our knowledge, no studies have compared outcomes of patients who undergo laparoscopic anastomotic repair in comparison to those who are treated by simple drainage and 
stoma, the so-called "divert and drain" technique [8]. The goal of our study is to compare re-laparoscopic lavage/ draingage + transanal endoluminal repair \pm stoma vs. drainage \pm stoma.

\section{Materials and methods}

This observational study was a retrospective chart review of all consecutive patients with anastomotic leakage after laparoscopic low anterior resection who underwent laparoscopic re-intervention between January 2013 and September 2020 at single tertiary center, China Medical University Hospital, Taichung, Taiwan.

Peritoneal contamination and collections were evaluated by abdominal computed tomographic (CT) scan and laparoscopy. Anastomotic leaks were defined clinically or identified during endoscopic/radiologic examination, abdominal CT [12] and confirmed by digital examination before re-intervention at the same time as evaluation of the defect size. Acute Physiology And Chronic Health Evaluation II (APACHE II) score was used to evaluate sepsis severity before the second operation.

Laparoscopic re-intervention was indicated when patients had symptomatic leaks including fever, peritonitis, unstable clinical status, and/or failure of conservative treatment. The Hartmann procedure was indicated when bowel tissue was not viable, anastomosis dehiscence $>50 \%$ of the circumference, associated with unstable clinical status. The decision to preserve the anastomosis and/or transanal endoluminal repair or create a stoma was taken according to surgeon experience and preference.

\section{Surgical technique}

The patients were placed in Trendelenburg position. The open technique was used to insert a $10 \mathrm{~mm}$ port through the previous umbilical port site to create the pneumoperitoneum and then insert the camera. Pneumoperitoneum pressure was maintained less than $12 \mathrm{~mm} \mathrm{Hg}$. All other $5 \mathrm{~mm}$ working ports were inserted via previous trocar wounds. Diagnostic laparoscopy was performed to visualize the entire abdominal cavity. After initial evaluation, blunt adhesiolysis with the suction irrigator and occasional sharp dissection using monopolar scissors or another energy-driven device was performed. All four quadrant were copiously lavaged with saline to eliminate all intra-abdominal collections.

After laparoscopic exploration, the defect size was confirmed by colonoscopy or transanal endoluminal examination. Transanal endoluminal repair of the dehiscence site was attempted with a TEO platform, as described previously [13] (Fig. 1). By direct transanal endoluminal examination, we were able to confirm the leak, assess the size of the dehiscence, the distance from the anal verge, and the vascular aspect of the mucosa of the adjacent colorectal segments (Fig. 1). The anastomotic leak site was closed with interrupted Vicryl ${ }^{\circledR} 2-0$ sutures (Fig. 1). The repair was visualized via the TEO or flexible colonoscopy, and tested for air-tightness. A diverting colostomy was performed in all patients who did not already have one during the initial operation (except one patient in the repair group).

Anastomotic healing was evaluated by digital examination every week during the 1st month and then flexible sigmoidoscopy every 3 months. Lastly, lower gastrointestinal imaging was performed before stoma closure.

Morbidity and mortality were recorded at 30 days after the second operation or during the same hospital stay. Surgical site infection (SSI) or organ space SSI was diagnosed by CT scan. Prolonged ileus was defined as absence of passage of flatus/stools $>7$ days.

Permanent stoma was defined as persistence of stoma $>1$ year after operation or at the time of death [14].

Categorical data are presented as numbers (percentages) and were compared with the Chi-square or Fisher's exact test, as appropriate. Continuous data are expressed as means for normally distributed variables, compared with the Student $t$-test or medians with ranges for nonparametric data and were compared with the MannWhitney U test.

All tests were two-sided and p values less than 0.05 were considered to be statistically significant. All statistical analyses were performed with SPSS for Windows (version 19.0; IBM-SPSS Inc., Armonk, NY).

\section{Results}

\section{Patient characteristics}

Between January 2013 and September 2020, 955 consecutive patients underwent laparoscopic low anterior resection with anastomosis in our Institution: 92 patients (9.6\%) were recorded as having an anastomotic leakage: 26 patients were treated conservatively, nine underwent percutaneous abscess drainage while 57 had laparoscopic reintervention (Fig. 2). Of the latter, the anastomosis was preserved in 49 patients while eight patients required resection (3 redo anastomoses and 5 Hartmann operations). The 49 patients with preservation constitute our study population: 22 underwent transanal endoluminal repair while 27 patients (control group) had drainage alone $(n=11)$ or with a stoma $(n=16)$, but no direct anastomotic repair. Patient baseline characteristics and details of the initial operation are indicated in Table 1.

\section{Immediate peri-laparoscopic reintervention outcome (Table 2)}

Median APACHE II score of all patients was 8 with no statistically significant difference between the two 


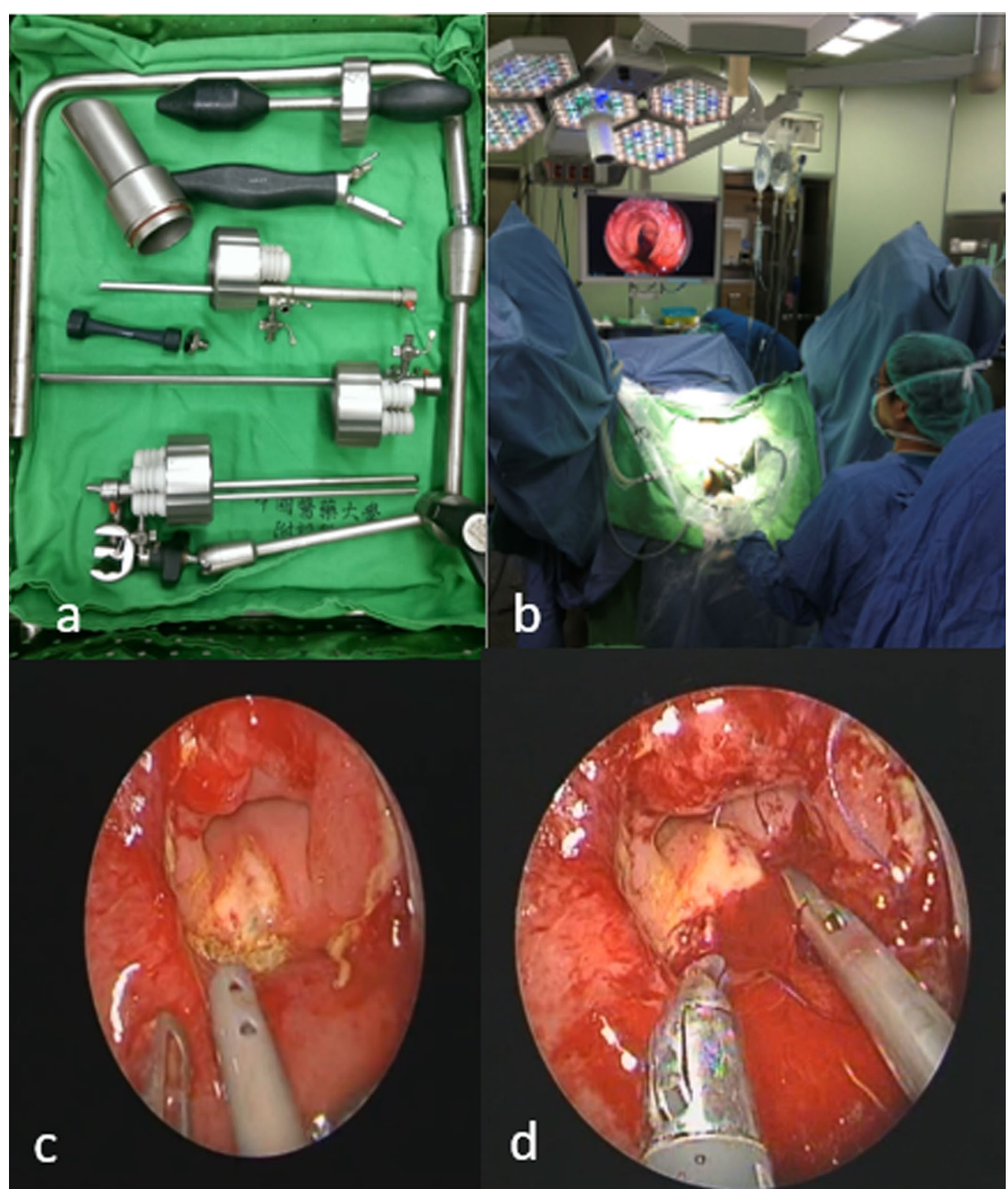

Fig. 1 Transanal endoluminal repair. a TEO platform. b Patient was under lithotomy position. c Irrigation over leakage site. d Transanal endoluminal repair with 3.0 Vicryl

groups. Three patients (13.6\%) in the repair group required conversion to open surgery (one due to inadequate exposure and two because of dense adhesions). One patient $(3.7 \%)$ in the control group was converted to laparotomy due to diffuse oozing of pelvic rough surface that was successfully controlled by compression after conversion. One patient in the repair group did not have stoma formation. The 30 day complication rate was statistically significantly lower in the repair group [3/22 patients (13.6\%) vs. $12 / 27$ patients $(44.4 \%)]$ in the control group, $\mathrm{p}=0.03)$. The intraabdominal infection rate was lower in the repair group ( $4.5 \%$ vs. $29.6 \%, p=0.03)$. The median hospital stay after the second operation was 10 (1-62) days; the difference between the two groups was not statistically significant.

\section{Complications and additional interventions related to the second operation (Tables 3 and 4)}

Fifteen patients had post-operative complications $(30.6 \%)$. Four patients sustained prolonged ileus 


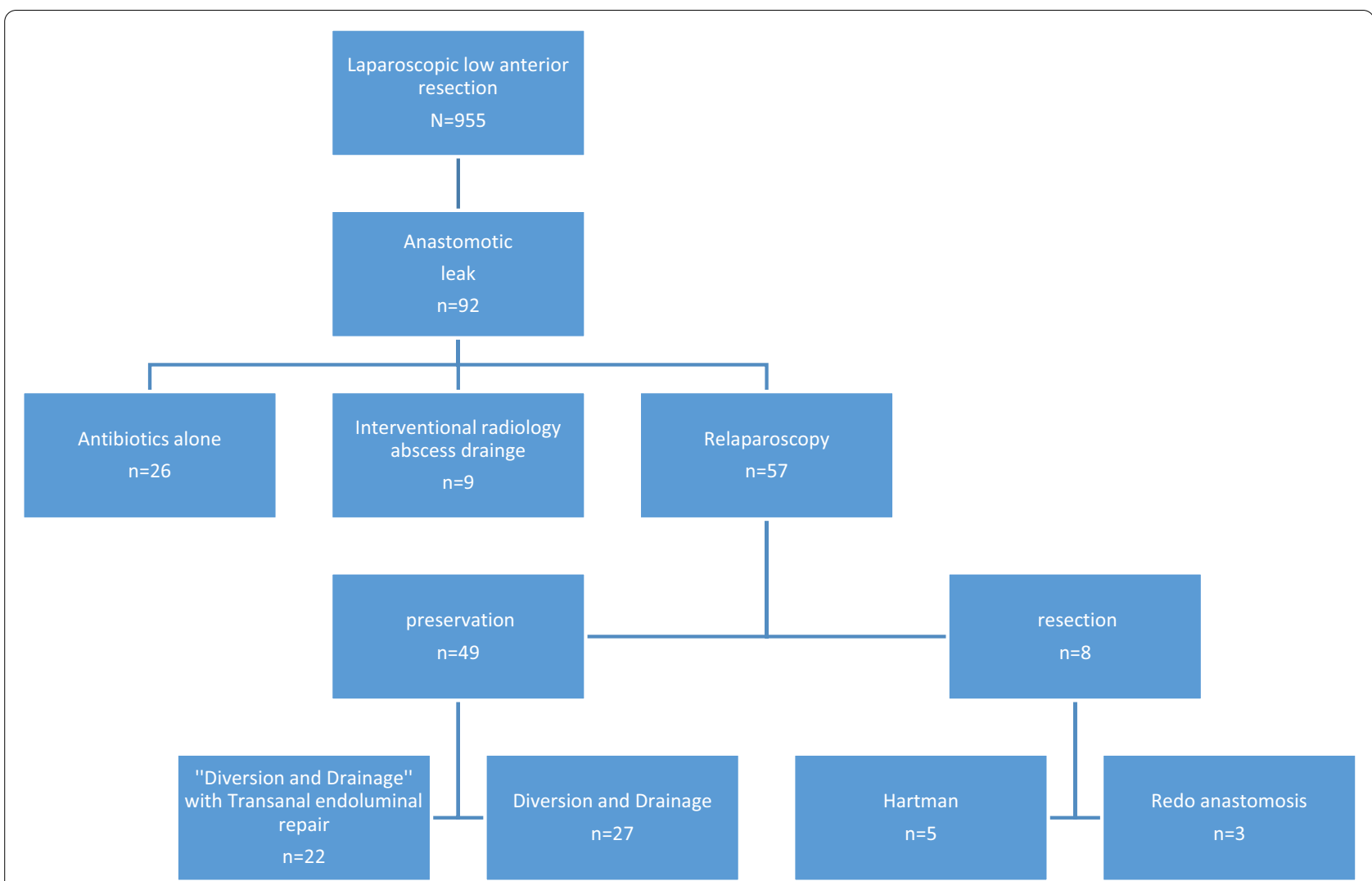

Fig. 2 Patient population flow chart

( $>7$ days); all were managed conservatively. Two patients in the repair group (who had been converted to open surgery) had surgical site infection (SSI) that was managed conservatively. One patient in the repair group had a deep organ/space intraabdominal infection (OS/SSI) vs. eight $(29.6 \%)$ in the control group. Immediate outcome of the re-laparoscopic operation with anastomotic preservation and additional interventions are indicated in Tables 3 and 4.

One patient developed a short $(<1 \mathrm{~cm})$ anastomotic stenosis 1 month after stoma closure which was managed by dilation as an outpatient. One patient developed stricture 2 months after transanal endoluminal repair and was managed by strictureplasty. Intra-operative bowel serosa tear occurred during adhesiolysis in two patients in the repair group: both were repaired immediately. In the control group, one patient had gastric ulcer and two patients sustained atelectasis. One patient died due to sepsis 62 days after the second operation.

Three patients (13.6\%) in the repair group required an additional intervention compared to five (18.5\%) in the control group but the difference was not statistically significant. The operations are indicated in Table 4.
Outcomes were uneventful in all eight patients (18.6\%) who required an additional intervention.

Four patients (18.2\%) in the repair group had a permanent stoma. The reasons why the stoma was not reversed were poor performance status and cancer progression in two patients each. Seven patients $(25.9 \%)$ in the control group did not have stoma reversal: the reasons were poor performance status in 3, persistent purulent discharge (including the patient who died) and cancer progression in two patients each. There were no other complications related to stoma closure. No anastomotic sinus, fistula, or recurrence was noted at 3-year follow up.

\section{Discussion}

Our study found that laparoscopic reintervention with anastomotic preservation for the management of colorectal anastomotic leakage was a viable option in 49 patients, thanks to early revisional surgery. The overall morbidity rate was $30.6 \%$ and one patient died (mortality rate $2 \%$ ). Combined laparoscopy and transanal endoluminal repair of anastomotic leakage was associated with a lower overall complication rate $(13.6 \%$ vs. $44.4 \%$, $\mathrm{p}=0.03$ ) and fewer deep/organ space intraabdominal 
Table 1 Baseline characteristics and details of first operation

\begin{tabular}{|c|c|c|c|c|}
\hline & All $(n=49)$ & Endoluminal repair $(n=22)$ & No repair $(n=27)$ & $P$ value \\
\hline Age & $60(32-89)$ & $56(32-87)$ & $66(32-89)$ & 0.10 \\
\hline BMl & $23.1(17.3-31.1)$ & $24.1(17.7-30.1)$ & $22.0(17.3-30.0)$ & 0.08 \\
\hline Gender & & & & 0.26 \\
\hline Male & $39(79.5 \%)$ & $17(77.3 \%)$ & $22(81.5 \%)$ & \\
\hline Female & $10(20.5 \%)$ & $5(22.7 \%)$ & $5(18.5 \%)$ & \\
\hline ASA & & & & 0.31 \\
\hline 2 & $33(67.3 \%)$ & $18(81.8 \%)$ & $15(55.6 \%)$ & \\
\hline 3 & $16(32.7 \%)$ & $4(18.2 \%)$ & $12(44.4 \%)$ & \\
\hline Malignant & $47(95.9 \%)$ & $20(90.9 \%)$ & $27(100 \%)$ & 0.24 \\
\hline Tumor site & & & & 0.17 \\
\hline Sigmoid & $5(6.3 \%)$ & $2(9.1 \%)$ & $3(11.1 \%)$ & \\
\hline Rectosigmoid & $9(18.3 \%)$ & $2(9.1 \%)$ & $7(25.9 \%)$ & \\
\hline Upper rectum & $11(22.4 \%)$ & $4(18.2 \%)$ & $7(25.9 \%)$ & \\
\hline Middle rectum & $12(26.5 \%)$ & $6(27.3 \%)$ & $6(22.2 \%)$ & \\
\hline Lower rectum & $12(26.5 \%)$ & $8(36.4 \%)$ & $4(14.8 \%)$ & \\
\hline Stage & & & & 0.68 \\
\hline । & $7(14.2 \%)$ & $4(18.18 \%)$ & $3(11.11 \%)$ & \\
\hline$\|$ & $10(20.4 \%)$ & $4(18.18 \%)$ & $6(22.22 \%)$ & \\
\hline III & $20(40.8 \%)$ & $9(40.91 \%)$ & $11(40.74 \%)$ & \\
\hline IV & $10(20.4 \%)$ & $3(13.64 \%)$ & $7(25.93 \%)$ & \\
\hline Neoadjuvant therapy & $11(22.4 \%)$ & $4(18.18 \%)$ & $7(25.9 \%)$ & 0.55 \\
\hline Stoma formation & & & & 0.23 \\
\hline 1st operation & $23(46.9 \%)$ & $12(54.5 \%)$ & $11(40.7 \%)$ & \\
\hline Anastomotic method & & & & 0.23 \\
\hline Stapled & $45(91.8 \%)$ & $20(90.9 \%)$ & $25(92.5 \%)$ & \\
\hline Handsewn & $4(8.2 \%)$ & $2(9.1 \%)$ & $2(7.5 \%)$ & \\
\hline $\begin{array}{l}\text { Distance of anastomosis from anal } \\
\text { verge }\end{array}$ & $5(0-18)$ & $4(0-12)$ & $6(0-18)$ & 0.61 \\
\hline
\end{tabular}

$B M I$ body mass index; ASA American Society of Anesthesiologists

Table 2 Patient characteristics before re-laparoscopy

\begin{tabular}{|c|c|c|c|c|}
\hline & All $(n=49)$ & Endoluminal repair $(n=22)$ & No repair $(n=27)$ & \\
\hline APACHE II score & $8(3-23)$ & $7(3-20)$ & $8(4-23)$ & 0.13 \\
\hline $\begin{array}{l}\text { Interval to detection of anastomotic leak } \\
\text { (days) }\end{array}$ & $5(1-17)$ & $4(1-13)$ & $4(1-17)$ & 0.54 \\
\hline Anastomotic defect & & & & 0.76 \\
\hline Total & $4(8.3 \%)$ & $2(9.09 \%)$ & $2(7.4 \%)$ & \\
\hline $1 / 2$ circumference & $6(12.2 \%)$ & $4(18.18 \%)$ & $2(7.4 \%)$ & \\
\hline $1 / 3$ circumference & $19(38.7 \%)$ & $8(36.36 \%)$ & $11(40.7 \%)$ & \\
\hline $1 / 4$ circumference & $20(40.8 \%)$ & $8(36.36 \%)$ & $12(44.4 \%)$ & \\
\hline Peritoneal contamination & & & & 0.47 \\
\hline Local & $33(67.3 \%)$ & $16(72.7 \%)$ & $17(62.9 \%)$ & \\
\hline Diffuse & $16(32.7 \%)$ & $6(27.3 \%)$ & $10(37.1 \%)$ & \\
\hline
\end{tabular}

infections ( $4.5 \%$ vs. $29.6 \%, p=0.03$ ) compared with the control group. Also, a lower permanent stoma rate was noted in the repair group compared to the no repair group (18.2\% vs. $25.9 \%, \mathrm{p}=0.73)$. 
Table 3 Intraoperative features and postoperative course after re-laparoscopy with anastomotic preservation

\begin{tabular}{|c|c|c|c|c|}
\hline & All $(n=49)$ & $\begin{array}{l}\text { Endoluminal repair } \\
(n=22)\end{array}$ & No repair $(n=27)$ & \\
\hline Blood loss units (cc) & $0(0-6650)$ & $0(0-30)$ & $0(0-6650)$ & 0.27 \\
\hline Stoma created during re-operation & $25(51.0 \%)$ & $9(40.9 \%)$ & $16(59.3 \%)$ & \\
\hline No stoma & $1(2.1 \%)$ & $1(4.6 \%)$ & 0 & \\
\hline Conversion & $4(8.1 \%)$ & $3(13.6 \%)$ & $1(3.7 \%)$ & 1.0 \\
\hline Post-operative complications & $15(30.6 \%)$ & $3(13.6 \%)$ & $12(44.4 \%)$ & 0.03 \\
\hline Ileus & $4(8.1 \%)$ & 0 & $4(14.8 \%)$ & 0.11 \\
\hline SSI & $4(8.1 \%)$ & $2(9.0 \%)$ & $2(7.4 \%)$ & 1.0 \\
\hline Deep OS/SSI & $9(18.3 \%)$ & $1(4.5 \%)$ & $8(29.6 \%)$ & 0.03 \\
\hline Anastomotic stricture & $2(4.0 \%)$ & $1(4.5 \%)$ & $1(3.7 \%)$ & 1.0 \\
\hline Persistent purulent discharge & $3(6.1 \%)$ & $2(9.0 \%)$ & $1(3.7 \%)$ & 0.58 \\
\hline Gastric ulcer & $1(2.0 \%)$ & 0 & $1(3.7 \%)$ & 1.0 \\
\hline Atelectasis & $1(2.0 \%)$ & 0 & $1(3.7 \%)$ & 1.0 \\
\hline Death & $1(2.0 \%)$ & 0 & $1(3.7 \%)$ & 1.0 \\
\hline Additional intervention (after second operation) & $8(16.3 \%)$ & $3(13.6 \%)$ & $5(18.5 \%)$ & 1.0 \\
\hline Surgical & $6(12.2 \%)$ & $3(13.6 \%)$ & $3(11.1 \%)$ & \\
\hline Non surgical & $2(4.0 \%)$ & 0 & $2(7.4 \%)$ & \\
\hline Median duration of hospital stay (days) & $9.5(1-62)$ & $11(1-45)$ & $9(3-62)$ & 0.68 \\
\hline Permanant stoma & $10(20.4 \%)$ & $4(18.2 \%)$ & $7(25.9 \%)$ & 0.73 \\
\hline Incisional hernia & $3(6.1 \%)$ & $2(5.9 \%)$ & $1(6.7 \%)$ & 0.71 \\
\hline
\end{tabular}

SSI surgical site infection; OS/SSI organ space surgical site infection

Table 4 Post-operative course after second operation

\begin{tabular}{|c|c|c|c|}
\hline & All $(n=49)$ & $\begin{array}{l}\text { Endoluminal } \\
\text { repair } \\
(n=22)\end{array}$ & No repair $(n=27)$ \\
\hline $\begin{array}{l}\text { Additional interven- } \\
\text { tion }\end{array}$ & $8(16.3 \%)$ & $3(13.6 \%)$ & $5(18.5 \%)$ \\
\hline $\begin{array}{l}\text { Surgical complica- } \\
\text { tions }\end{array}$ & $6(12.2 \%)$ & $3(13.6 \%)$ & $3(11.1 \%)$ \\
\hline Abscess drainage & 2 & 1 & 1 \\
\hline $\begin{array}{l}\text { Hartmann proce- } \\
\text { dure }\end{array}$ & 1 & 0 & 1 \\
\hline Redo anastomosis & 1 & 0 & 1 \\
\hline Stricureplasty & 1 & 1 & 0 \\
\hline Debridement & 1 & 1 & 0 \\
\hline $\begin{array}{l}\text { Non surgical compli- } \\
\text { cations }\end{array}$ & 2 & 0 & 2 \\
\hline $\begin{array}{l}\text { Interventional } \\
\text { radiology (abscess } \\
\text { drainage) }\end{array}$ & 1 & 0 & 1 \\
\hline Gastroscopy & 1 & 0 & 1 \\
\hline
\end{tabular}

In the absence of consensus on standardized management of colorectal anastomosis leakage, some authors would argue that patients with stoma or localized abscess should been managed conservatively or undergo percutaneous drainage without reoperation $[15,16]$. However, definitive closure of leaks with these methods can take several weeks, or be complicated with sinus formation or fistula $[17,18]$. Laparoscopic reintervention for anastomotic leakage after laparoscopic colorectal surgery has gained widespread acceptance and several reports have shown that it is safe $[13,15,19-22]$. Traditionally, management for anastomotic leakage was via laparotomy because of the fear of bowel injury due to distended bowel and/or inadequate exposure through the laparoscopic approach [13]. In our series, two patients had serosal injury which were repaired immediately; both patients had undergone late reintervention ( $>5$ days), that is recognized as a cause of bowel distension, dense adhesions and inadequate visualization [13]. This is an argument in favor of early reintervention. Compared to relaparotomy, laparoscopic reintervention has the advantage of reduced wound complications (infection and incisional hernia) $[15,19,20]$ and maintains the advantages of laparoscopic surgery [23]. Indeed, as in our series, the previous trocar wounds can be reused for laparoscopic reintervention and the minilaparotomy wound does not have to be re-opened. There were three patients who had surgical site infection and three patients with ventral hernia in our series. All six patients with wound complications were patients who had undergone conversion.

Another concern of laparoscopic reintervention for leaks has been that pneumoperitoneum would cause fecal ascites and then exacerbate intra-abdomen infection 
[21]. However, several studies have shown that laparoscopy does not increase intra-abdomen infection when compared with laparotomy [16, 20]. Lee et al. reported a $6.6 \%$ intra-abdominal infection rate after laparoscopic reintervention compared to $31.3 \%$ in the open group [20]. However, there was no clear definition of intra-abdomen infection or the additional interventions related to intraabdomen infection. Although intraabdominal infection was the major complication after laparoscopic reintervention in our series, all patients had an uneventful recovery after either conservative therapy or additional intervention.

Most studies on laparoscopic reintervention for colorectal anastomosis leakage have recommended "divert and drain" with anastomosis preservation $[13,14,19,20]$. Reports of colorectal anastomosis repair are rare [13, 20, 22 ]. Lee et al. reported 61 laparoscopic reinterventions for colorectal anastomosis leakage: 12 patients had trans anal repair [20]. However, the authors did not describe the outcome after anastomotic repair. Brunner et al. reported two patients who underwent trans anal repair with a single-port device (SILSTM Port CovidienTM); no stoma was performed [22] similar to our previously reported technique [13].

Our overall permanent stoma rate was $20.4 \%$ (10/49), similar to other studies $[14,16,20]$. This includes both the patients with stoma formation at the original operation (created according to patient status and surgeon preferences) and those who received a stoma at the reoperation. Of note, although there were fewer patients with permanent stoma in the repair group (18.2\% vs. $25.9 \%)$, the difference was not statistically significant. When complicated by sinus formation and/or fistula, diverting stoma and simple drainage without repair may lead to delayed or no stoma closure [17]. None of our patients had sinus formation or late fistula. Furthermore, intestinal healing after anastomotic leak can be associated with intense fibrosis and eventually some degree of anastomotic stricture [24, 25]. We believe that early repair could possibly avoid these complications or at least reduce the inflammatory response associated with their persistence. The improved post-operative course with fewer intraoperative complications may explain why more patients in our series were scheduled for stoma reversal. However, our numbers are small and long term follow-up is needed.

Our morbidity rate $(30.6 \%)$ is at the lower limit of the range reported in the literature [19, 25, 26]. However, none of these studies concerned the outcome of transanal endoluminal repair. Morbidity in the control (no-repair) group was high $(13.6 \%$ vs. $44.4 \%, \mathrm{p}=0.03)$ although there was no difference in APACHE II score (7.9 vs. $10.3, p=0.12$ ), anastomotic defect characteristics, or diffuse peritoneal contamination $(27.3 \%$ vs. $37.1 \%$, $\mathrm{p}=0.47$ ) between the two groups. Possible explanations include the higher deep O/S SSI rate in the control group $(29.6 \%$ vs. $4.5 \%, \mathrm{p}=0.03)$. When the anastomotic site is not repaired, it is possible that the leaking site could still be an active source of infection, even though the leak will eventually heal. Endoscopic vacuum-assisted closure has been reported as viable option to deal with anastomotic leak after low anterior resection with effective control of septic focus [27]. However, the duration of treatment can be long (34.4 \pm 19.4 days) [27]. Although we have no formal proof, we believe that the ease with which the leak can be assessed and repaired endo-luminally (vs. trans abdominal laparotomy or laparoscopy) are strong arguments in favor of the transanal endoluminal route for extraperitoneal colorectal anastomosis leakage repair and could decrease the intraabdominal infection rate associated with laparoscopic reintervention. Indeed, intraabdominal infection is the main complication after laparoscopic reintervention and it is also the main reason for additional interventions after reoperation $[19,20]$. In our study, all patients who had O/S SSI (including four patients after additional intervention) could be managed safely by antibiotics, radiological drainage or re-laparoscopy. There was no statistically significant difference in additional intervention rates, hospital stay or outcomes between two groups.

Our study has several limitations. This study was retrospective, and the sample size was small $(n=49)$. Although there were variations in the stage of disease stage and the distance of the anastomosis from the anal verge, these differences were not statistically significant. As well, there was no statistically significant difference in outcome between the two groups in spite of these variations as well as to whether leakage occurred early or late, or the technique of anastomosis at primary surgery. In addition, the indication for transanal endoluminal repair and stoma creation was made at the surgeon's discretion. Although it may be argued that many patients with anastomotic leak after anterior resection may be suitable for conservative treatment, this may prolong hospital stay, delay reintervention or compromise stoma reversal. According to our experience, re-laparoscopy is an early diagnostic tool for anastomosis leakage and transanal endoluminal repair is easier when re-operation is early $[12,13]$ because bowel tissues become more inflamed, and adhesions are firmer when the intervention is performed at a later stage.

\section{Conclusions}

This series confirms that laparoscopic reintervention with anastomotic preservation is safe and feasible for anastomotic leakage after low anterior resection. 
Furthermore, transanal endoluminal repair is effective in the management of colorectal anastomosis leakage under specific circumstances. Compared to controls (no repair), transanal endoluminal repair was associated with lower morbidity and in particular, OS/ISS; the permanent stoma rate was lower. However, our sample size was small and these promising results need to be reproduced in larger and ideally randomized studies comparing transanal endoluminal anastomotic repair to drainage (with or without stoma).

\section{Acknowledgements}

Not applicable.

\section{Authors' contributions}

YCC, AF, WTLC were substantial contributions to the conception of the work and YCC, YYT, TWK analyzed the data. YCC, YYT, TWK drafted the work and AF, WTLC revised it critically for important intellectual content. All authors approved of the version to be published and agreement to be accountable for all aspects of the work in ensuring that questions related to the accuracy or integrity of any part of the work are appropriately investigated and resolved. All authors fulfil the ICMJE criteria. All authors read and approved the manuscript.

\section{Funding}

This research did not receive any specific grant from funding agencies in the public, commercial, or not-for-profit sectors.

\section{Availability of data and materials}

Data sharing is not applicable to this article as no datasets were generated or analyzed.

\section{Declarations}

\section{Ethics approval and consent to participate}

The study was approved by the departmental and institutional ethical committees of the China Medical University Hospital, Taichung, Taiwan (CMUH110REC1-039). All methods were performed in accordance (for example: declaration of Helsinki) with the relevant guidelines and regulations. Informed consent was not required due to retrospective design and granted exemption from IRB review (CMUH1 10-REC1-039).

\section{Consent for publication}

Not applicable.

\section{Competing interests}

The authors declare no competing interests.

\section{Author details}

'Department of Colorectal Surgery, China Medical University Hospital, Taichung, Taiwan. ${ }^{2}$ Department of General Surgery, Ruijin Hospital, Shanghai Jiao Tong University School of Medicine, Shanghai Minimally Invasive Surgery Center, Shanghai 200025, People's Republic of China. ${ }^{3}$ Medical University Hospital of Graz, Graz, Austria. ${ }^{4}$ China Medical University Hsinchu Hospital, Zhubei, Taiwan.

Received: 17 October 2021 Accepted: 7 January 2022

Published online: 26 January 2022

\section{References}

1. Krarup PM, Jorgensen LN, Andreasen AH, Harling H. A nationwide study on anastomotic leakage after colonic cancer surgery. Colorectal Dis. 2012;14:e661-7.
2. Eriksen MT, Wibe A, Norstein J, Haffner J, Wiig JN. Anastomotic leakage following routine mesorectal excision for rectal cancer in a national cohort of patients. Colorectal Dis. 2005;7:51-7.

3. Merkel S, Wang WY, Schmidt O, Dworak O, Wittekind C, Hohenberger W, Hermanek P. Locoregional recurrence in patients with anastomotic leak after anterior resection for rectal carcinoma. Colorectal Dis. 2001;3:154-60.

4. Chang SC, Lin JK, Yang SH, Jiang JK, Chen WC, Lin TC. Long-term outcome of anastomosis leak after curative resection for mid and low rectal cancer. Hepatgastroenterology. 2003;50:1898-902.

5. Soeters PB, de Zoete JP, Dejong CH, Williams NS, Baeten CG. Colorectal surgery and anastomotic leakage. Dig Surg. 2002;19:150-5.

6. Bertelsen CA, Andreasen AH, Jorgensen T, Harling H. Anastomotic leakage after anterior resection for rectal cancer: risk factors. Colorectal Dis. 2010;12:37-43.

7. Slieker JC, Daams F, Mulder IM, Jeekel J, Lange JF. Systematic review of the technique of colorectal anastomosis. JAMA Surg. 2013;148:190-201.

8. Blumetti J, Chaudhry V, Cintron JR, Park JJ, Marecik S, Harrison JL, Prasad LM, Abcarian H. Management of anastomotic leak: lessons learned from a large colon and rectal surgery training program. World J Surg. 2014;38:985-91.

9. Marinatou A, Theodoropoulos GE, Karanika S, Karantanos T, Siakavellas S, Spyropoulos BG, Toutouzas K, Zografos G. Do anastomotic leaks impair postoperative health-related quality of life after rectal cancer surgery? A case-matched study. Dis Colon Rectum. 2014;57:158-66.

10. Beck DE, Wexner SD, Hull TL, Roberts PL, Saclarides TJ, Senagore AJ, Stamos MJ, Steele SR. ASCRS manual of colon and rectal surgery. New York: Springer; 2014.

11. Blumetti J, Abcarian $\mathrm{H}$. Management of low colorectal anastomotic leak: preserving the anastomosis. World J Gastrointest Surg. 2015;27:378-83.

12. Chen WT-L, Fingerhut A. Minimal access surgery has its place in the treatment of anastomotic leakage after anterior resection: suggestion for a modification of the International Study Group of Rectal Cancer (ISREC) classification. Surgery. 2021;170(1):345-6. https://doi.org/10.1016/j.surg. 2021.02.044.

13. Chen WT, Bansal S, Ke TW, Chang SC, Huang YC, Kato T, Wang HM, Fingerhut A. Combined repeat laparoscopy and transanal endolumenal repair (hybrid approach) in the early management of postoperative colorectal anastomotic leaks: technique and outcomes. Surg Endosc. 2018;32:4472-80

14. Boyce SA, Harris C, Stevenson A, Lumley J, Clark D. Management of low colorectal anastomotic leakage in the laparoscopic era: more than a decade of experience. Dis Colon Rectum. 2017;60:807-14.

15. Creavin B, Ryan EJ, Kelly ME, Moynihan A, Redmond CE, Ahern D, Kennelly R, Hanly A, Martin ST, O'Connell PR, Brophy DP, Winter DC. Minimally invasive approaches to the management of anastomotic leakage following restorative rectal cancer. Colorectal Dis. 2019;21:1364-71.

16. Joh YG, Kim SH, Hahn KY, Stulberg J, Chung CS, Lee DK. Anastomotic leakage after laparoscopic protectomy can be managed by a minimally invasive approach. Dis Colon Rectum. 2009;52:91-6.

17. Van Koperen PJ, van der Zaag ES, Omloo JM, Slors JF, Bemelman WA. The persisting presacral sinus after anastomotic leakage following anterior resection or restorative proctocolectomy. Colorectal Dis. 2011;13(26-29):28.

18. Buskens CJ, Bemelman WA, Tanis PJ. Treatment of chronic presacral sinus after low anterior resection. Colorectal Dis. 2013;15:727-32.

19. Wind J, Koopman AG, van Berge Henegouwen MI, Slors JF, Gouma DJ, Bemelman WA. Laparoscopic reintervention for anastomotic leakage after primary laparoscopic colorectal surgery. Br J Surg. 2007;94:1562-6.

20. Lee CM, Huh JW, Yun SH, Kim HC, Lee WY, Park YA, Cho YB, Chun HK. Laparoscopic versus open reintervention for anastomotic leakage following minimally invasive colorectal surgery. Surg Endosc. 2015;29:931-6.

21. Targarona E, Balague C, Knook M, Trias M. Laparoscopic surgery and surgical infection. Br J Surg. 2000;87:536-44.

22. Brunner W, Rossetti A, Vines LC, Kalak N, Bischofberger SA. Anastomotic leakage after laparoscopic single-port sigmoid resection: combined transanal and transabdominal minimal invasive management. Surg Endosc. 2015;29:3803-5.

23. Chang KH, Bourke MG, Kavanagh DO, Neary PC, O'Riordan JM. A systematic review of the role of re-laparoscopy in the management of complications following laparoscopic colorectal surgery. Surgeon. 2016;14:287-93. 
24. Davis B, Rivadeneira DE. Complications of colorectal anastomoses: leaks, strictures, and bleeding. Surg Clin N Am. 2013;93:61-87.

25. Lamazza A, Fiori E, Schillaci A, Sterpetti AV, Lezoche E. Treatment of anastomotic stenosis and leakage after colorectal resection for cancer with self-expandable metal stents. Am J Surg. 2014;208:465-9.

26. Cuccurullo D, Pirozzi F, Sciuto A, Bracale C, La Barbera C, Galante F, Corcione F. Relaparoscopy for management of postoperative complications following colorectal surgery: ten years experience in a single center. Surg Endosc. 2015:29(7):1795-803.

27. Weidenhagen R, Gruetzner KU, Wiecken T, Spelsberg F, Jauch KW. Endoscopic vacuum-assisted closure of anastomotic leakage following anterior resection of the rectum: a new method. Surg Endosc. 2007. https://doi.org/10.1007/s00464-007-9706-x.

\section{Publisher's Note}

Springer Nature remains neutral with regard to jurisdictional claims in published maps and institutional affiliations.

- fast, convenient online submission

- thorough peer review by experienced researchers in your field

- rapid publication on acceptance

- support for research data, including large and complex data types

- gold Open Access which fosters wider collaboration and increased citations

- maximum visibility for your research: over 100M website views per year

At BMC, research is always in progress.

Learn more biomedcentral.com/submissions 